\title{
A POLÍTICA DE EDUCAÇÃO ESPECIAL NA ERA LULA (2003-2011): UMA OPÇÃO PELA INCLUSÃO
}

\section{RESUMO}

Caio Augusto Toledo Padilha ${ }^{1}$

Este artigo analisa a atuação do governo Luiz Inácio Lula da Silva (2003-2011) no campo educacional, mais especificamente na Educação Especial. Em oito anos de mandato, o presidente e sua equipe implementaram programas e ações governamentais de combate à desigualdade social e de reconhecimento, possibilitando que se avançasse, não sem contradições, em diferentes campos e, mais especificamente, no campo educacional, na construção de um sistema que incorporasse todos os indivíduos à escola comum, de modo a efetivar o direito garantido pela Constituição de 1988.

Palavras-chave: Política Educacional; História da Educação; História das Políticas Educacionais; Governo Luiz Inácio Lula da Silva (2003-2011); Educação Especial

\section{THE SPECIAL EDUCATION POLICY IN THE AGE LULA (2003-2011): AN OPTION FOR INCLUSION}

\begin{abstract}
This article analyzes Luiz Inacio Lula da Silva's government (2003-2011) in the educational field, more specifically in Special Education. In the eight years of his term, the president and his team implemented programs and government actions to obtain recognition and fight social inequality, making progress possible, more specifically, in education, and in building a system that incorporated all individuals to the regular school, in order to effect the right granted by the 1988 Constitution.

Keywords: Educational Policy; History of Education; History of Educational Policy; Government of Luiz Inacio Lula da Silva (2003-2011); Special Education
\end{abstract}

\section{Introdução}

Neste $\operatorname{artigo}^{2}$ tem-se por objetivo analisar a atuação do presidente Luiz Inácio Lula da Silva e de sua equipe de governo no decorrer dos dois mandatos presidenciais à frente da área educacional, de modo a identificar as ações concernentes à Educação Especial, para estabelecer os possíveis avanços e retrocessos na efetivação do direito de todos os indivíduos à educação.

Trata-se de um estudo histórico, que como atenta Saviani (2010, p. 04), não é desinteressado, pois "o que provoca o impulso investigativo é a necessidade de responder a alguma questão que nos interpela na realidade presente", de modo que nos desperta a "própria consciência da historicidade humana, isto é, a percepção de que o presente se enraíza no passado e se projeta no futuro". Isto posto, esforcei-me em realizar uma pesquisa qualitativa, voltada à análise de conteúdo de fontes primárias (diferentes documentos nacionais), que tornam possível identificar, com maior clareza, aquilo que foi formulado pela administração Lula em matéria de política educacional e fontes secundárias (produções bibliográficas acerca das diferentes temáticas abordadas), cujos dados foram compilados e analisados criticamente, de acordo com uma compreensão da educação como um fenômeno concreto, influenciado por fatores econômicos, políticos, sociais e culturais; 
das políticas públicas como intervenções estatais no sentido de satisfazer demandas da sociedade mediante a realização de determinadas ações e; da inclusão escolar, como um fenômeno necessário à democratização da educação no país.

Compreende-se aqui, por inclusão, a inserção total do alunado na escola comum, num claro desafio, que coloca em xeque a dicotomia "opressor-oprimido" já denunciada por Paulo Freire (2013) e o conjunto de teorias pedagógicas disseminadas pelo sistema capitalista nas últimas décadas (tecnicismo, neotecnicismo, neoprodutivismo, neoescolanovismo, "pedagogia das competências", etc.), deveras criticadas por Saviani (2010). Portanto, em tempos de mobilização social pró e contra a inclusão, é necessário estabelecer uma análise de como o Estado tem atuado no campo educacional para efetivar o direito de todos a uma educação pública, laica, gratuita e de qualidade a todos os indivíduos.

Apresento esse artigo em quatro seções. Na primeira, estabeleço um breve panorama da era Lula, de modo a apresentar sua ascensão ao poder, condução das políticas econômica e social, e atuação na área educacional. Na segunda, centro a análise na política de educação especial implementada durante o primeiro mandato. Na terceira, volto-me à análise da política de educação especial do segundo mandato. Por fim, na quarta e última seção, apresento minhas considerações finais, com vistas a apontar se houve avanços ou retrocessos na democratização da oferta dos serviços educacionais para as pessoas com deficiência.

\section{Um breve panorama da era Lula (2003-2011)}

Luiz Inácio Lula da Silva chegou à Presidência da República em 2002 após três tentativas frustradas (1989, 1994 e 1998). Filiado ao Partido dos Trabalhadores (PT), Lula representava uma candidatura ligada ao espectro político da esquerda dentro de um partido que, no decorrer do tempo, modificara sua postura política ao ampliar o diálogo com os diferentes setores da sociedade, profissionalizar a estrutura, isolar as correntes radicais e dedicar-se com afinco aos pleitos eleitorais (AMARAL, 2010). Assim, chegara ao pleito de 2002 em condições de aliar-se ao Partido Liberal (PL), atrair um empresário para a chapa presidencial (José Alencar) e lançar um documento - a "Carta ao Povo Brasileiro" -, cujo teor reforçava o propósito de implementar uma política econômica que respeitasse os "contratos e obrigações do país", promovesse o combate à inflação, preservasse o superávit primário o quanto fosse necessário "para impedir que a dívida interna aumente e destrua a confiança na capacidade do governo de honrar seus compromissos" (SILVA, 2002, s/p).

Ao chegar ao poder, valendo-se de uma "estratégia de marketing político" que o mostrou como "conciliador, trajado de modo elegante e amparado por uma equipe de estudiosos e técnicos de grande qualidade" (FIGUEIREDO e COUTINHO, 2003, p. 114), Lula superou as resistências conservadoras e venceu José Serra (PSDB) no segundo turno, assumindo o primeiro mandato como presidente da República em 01 de janeiro de 2003.

O primeiro mandato foi marcado pela manutenção da política macroeconômica do antecessor, ancorada no tripé - sistema de metas de inflação, regime de câmbio flutuante e manutenção de superávits primários nas contas públicas (POCHMANN, 2011) -, que seria conduzida por uma equipe econômica com "formação ortodoxa e/ou passagem pelo sistema financeiro nacional e internacional" (NOVELLI, 2010, p. 236), o que fez com que o novo governo conquistasse credibilidade no plano externo, mas sofresse críticas de aliados históricos num primeiro momento. Tempos depois, mesmo com o elevado endividamento interno, a inflação voltou a cair, o endividamento externo diminuiu 
sensivelmente, os preços das commodities foram alavancados e o país tornou-se atrativo aos investimentos estrangeiros.

O segundo mandato, conquistado após desgastante campanha, impactada pelas denúncias de esquemas de corrupção amplamente divulgados pela imprensa, foi conferido pelas urnas na vitória contra Geraldo Alckmin (PSDB) em segundo turno no dia 29 de outubro de 2006. Amparado pelo carisma, pela avaliação positiva do governo que presidia e tendo recebido expressiva votação no segundo turno - mais de $60 \%$ dos votos válidos -, Lula e sua equipe encontraram uma conjuntura mais favorável, tanto no campo político como no econômico, para colocar em prática a prometida agenda desenvolvimentista.

Ações como a implantação da política de valorização real do salário mínimo, a ampliação do abono salarial e a utilização dos bancos estatais para a expansão do microcrédito e das microfinanças - provocando a inserção de milhões de brasileiros no ciclo econômico -; a redefinição da política externa (fortalecimento do MERCOSUL, ampliação do relacionamento com países africanos e asiáticos); o estímulo ao comércio exterior; redução da taxa de juros; desoneração de tributos para o setor produtivo; o estabelecimento de uma política de desenvolvimento regional (recriação das superintendências regionais); a implementação do Programa de Aceleração do Crescimento (PAC), que previa investimentos em infraestrutura, de modo a recuperar a capacidade de atuação estatal em setores estratégicos para o desenvolvimento após mais de uma década de neoliberalismo; dentre outras importantes ações - fizeram com que o país aquecesse a economia e colhesse à metade do segundo mandato de Lula os resultados do "ciclo virtuoso".

Em articulação com as ações no campo econômico, o governo pôs-se a implementar um amplo conjunto de políticas sociais, responsável por incorporar demandas historicamente reprimidas. A partir disso, o governo Lula procurou garantir a representação de amplos segmentos da sociedade na formulação e na apreciação de políticas públicas ao aprofundar as relações com a sociedade civil e suas organizações (movimentos sociais, sindicatos, associações, organizações não-governamentais, organizações da sociedade civil de interesse público (OSCIP), fundações, etc.) e estimular a criação de novos mecanismos de participação social - fóruns, conferências e conselhos temáticos - que trouxeram à agenda governamental pautas favoráveis à igualdade de gênero, à igualdade racial, às causas da população indígena, LGBT (Lésbicas, Gays, Bissexuais, Travestis, Transexuais e Transgêneros), das pessoas com deficiência, entre outros.

Intervenções profícuas se sucederam nas áreas de saúde, assistência social, habitação, infraestrutura urbana, cultura e agricultura, combinadas às políticas de combate à fome e à miséria, inicialmente articuladas no programa Fome Zero, que rapidamente foi substituído pelo Bolsa Família. Este programa de transferência de renda, destinado às famílias em situação de pobreza e de extrema pobreza, unificou os programas anteriores (Bolsa Alimentação, Auxílio Gás, Bolsa Escola e Cartão Alimentação), impôs condicionalidades - matrícula e manutenção de crianças e adolescentes em idade escolar nas redes de ensino e acompanhamento de gestantes, nutrizes e crianças nos postos de saúde -, e tornou-se um importante instrumento no combate à desigualdade.

Na esteira do Bolsa Família, vieram ainda a Agenda Social, instrumento criado para melhor articular as ações setoriais no campo social, a partir da implementação de programas voltados aos públicos considerados mais vulneráveis - crianças e adolescentes, pessoas com deficiência, mulheres, quilombolas, indígenas -, nas áreas da saúde, cultura, segurança, direitos de cidadania, assistência social, segurança alimentar e nutricional, transferência de renda e educação e, finalmente, o Territórios da Cidadania, cuja função 
seria o combate à pobreza em meios rurais a partir da formulação de parcerias com os municípios e organizações sociais, mediante ações voltadas à sustentabilidade, à inclusão produtiva, à saúde, à infraestrutura básica, à cultura e à educação, entre outros setores.

$\mathrm{Na}$ educação, muito se esperava do PT devido à sua ligação orgânica com o setor educacional, pois afirmara a defesa da educação pública como um princípio desde a sua fundação e, em decorrência disso, atraíra educadores e intelectuais para os seus quadros (LEHER, 2010). Apesar disso, o que se viu foi a adoção de uma agenda controversa, que combinou a manutenção de propostas neoliberais com a inserção de temas progressistas. A descontinuidade da gestão não impediu, todavia, que o governo Lula viesse a atuar junto aos diferentes níveis de ensino e modalidades educacionais.

Daí a elaboração de um vasto conjunto de realizações. A começar do financiamento da educação, que teve um de seus principais mecanismos de financiamento alterado com a criação do Fundo de Manutenção e Desenvolvimento da Educação Básica e de Valorização dos Profissionais da Educação (FUNDEB) em substituição ao Fundo de Manutenção e Desenvolvimento do Ensino Fundamental e de Valorização do Magistério (FUNDEF). Embora o novo fundo tenha trazido poucos recursos novos ${ }^{3}$ para a educação, consistiu em inovação, pois alterou a estratégia de focalização no Ensino Fundamental ao incorporar toda a educação básica. Isso fez com que os níveis de ensino e modalidades educacionais historicamente ignorados viessem a ter maior espaço na divisão dos recursos estatais, apesar das restrições orçamentárias.

Ainda nesse esforço de ação conjunta, foi formulado, como parte da Agenda Social, o Plano de Desenvolvimento da Educação (PDE), um "plano coletivo de médio e longo prazos, sistêmico, que propõe um novo regime de colaboração e busca aprimorar a atuação dos entes federados sem ferir-lhes a autonomia" (SILVA, 2010, p. 162) ${ }^{4}$, mediante a implementação de um conjunto de medidas que se organizaria em quatro grandes eixos educação básica; alfabetização e educação continuada; ensino profissional e tecnológico; e Ensino Superior - e estabelecer diferentes ações que deveriam ser implementadas pelo governo federal. Como parte do PDE, seria ainda criado o Plano de Metas Compromisso Todos pela Educação, que disporia as diretrizes a serem cumpridas por estados, municípios e pelo Distrito Federal em seus respectivos sistemas de ensino de modo a contemplar as exigências da União ${ }^{5}$.

No que tange, especificamente, aos níveis de ensino e modalidades educacionais, o governo empreendeu uma série de programas e ações.

A Educação Infantil completou seu processo de transição para a área educacional. Foram criadas a nova política educacional, as Diretrizes Curriculares Nacionais e os Indicadores de Qualidade para a modalidade; o Proinfância; e a modalidade ainda foi incluída nos diferentes programas do Ministério da Educação (muitos dos quais foram mantidos, ampliados e estendidos a outros níveis de ensino). O Ensino Fundamental, por sua vez, foi objeto da controversa extensão de sua duração para 9 anos; mecanismos de avaliação foram criados como a Prova Brasil, a Provinha Brasil, a Avaliação Nacional da Educação Básica e o Índice de Desenvolvimento da Educação Básica (IDEB) ${ }^{6}$ - que preservaram a indução de um conceito de qualidade consoante à lógica mercadológica, e não só mantiveram as práticas de responsabilização das instituições de ensino, como também recrudesceram a competição entre elas (FREITAS, 2007) - e o programa Mais Educação foi criado com o objetivo de ampliar a jornada escolar e reorganizar o currículo escolar na perspectiva da Educação Integral.

O combate ao analfabetismo fez-se através de um novo programa, o Brasil Alfabetizado e o fim à dicotomização entre a educação básica e a educação profissional fez com que a educação de jovens e adultos ganhasse novo espaço na agenda com a criação de 
vários programas - dentre os quais, o Programa Nacional de Integração da Educação Profissional com a Educação Básica na Modalidade da Educação de Jovens e Adultos (PROEJA) - e se desse início a um período de grande expansão das escolas técnicas e agrotécnicas. Já o Ensino Médio, historicamente dual - "escola secundária para os dirigentes e profissional para preparar os quadros do trabalho" (NOSELLA, 2011, p. 4) teve seu currículo rediscutido, foi considerado obrigatório a partir da Emenda Constitucional n. 59 de 2009, e o Exame Nacional do Ensino Médio (ENEM) foi convertido em instrumento de certificação para jovens e adultos e de seleção de alunos para as universidades federais.

O MEC, durante o período Lula, não restringiu sua atuação à promoção de políticas de caráter redistributivo, que visavam à promoção da inclusão na perspectiva da classe social, e implementou, também, políticas de reconhecimento, encaminhadas pelos movimentos "feministas, étnicos, dos portadores de deficiência, cujo emblema tem sido a educação para todos com equidade social" (OLIVEIRA, 2011, p. 32). Desse processo culminaram importantes resoluções como a elaboração do Plano Nacional de Educação em Direitos Humanos e, mais especificamente, para a Educação Indígena e a Educação Quilombola: a Lei n. 10.639 de 9 de janeiro de 2003, que tornou obrigatória a inclusão, no currículo escolar, do ensino de História e Cultura Afro-Brasileira; o Conexões de Saberes ${ }^{7}$; o encaminhamento do projeto de Lei n. 3267 de $2004^{8}$; a implementação dos programas de formação de professores para as modalidades e a incorporação destas nos demais programas do ministério, dentre outras ações, que, contudo, acabaram não alcançando os resultados esperados em função, sobretudo, da fragmentação e das limitações orçamentárias (MOEHLECKE, 2009).

No bojo dessas realizações, o MEC tomou duas medidas que impactariam diretamente a educação básica: a elaboração da Lei n. 11.738 de 16 de julho de 2008 e o estabelecimento das Diretrizes Curriculares Nacionais Gerais para a Educação Básica.

A Lei instituiu o piso salarial nacional, a ser respeitado pelos estados e municípios e aplicado às aposentadorias e pensões; estabeleceu que os docentes deveriam cumprir, no máximo, 2/3 da jornada de trabalho com o alunado; assegurou a atualização anual dos vencimentos; e impôs aos entes federados a elaboração - ou adequação - dos Planos de Carreira e Remuneração do Magistério até 2009.

As Diretrizes Curriculares Nacionais Gerais para a Educação Básica (parecer do Conselho Nacional de Educação e da Câmara de Educação Básica n. 7/2010 e resolução dos mesmos órgãos n. 4/2010) reafirmaram o compromisso estatal com a garantia do direito de todos os indivíduos à educação; à preparação para o exercício da cidadania e à qualificação para o trabalho; a promoção de políticas de democratização do acesso e permanência de crianças, jovens e adultos na instituição educacional; o regime de colaboração entre os entes federativos; a necessidade de garantir a qualidade social da educação através da transformação do estudante e da aprendizagem em elementos centrais do processo educativo; e com uma concepção de educação pautada não só nos pressupostos constitucionais, mas, na "cidadania e na dignidade da pessoa, o que pressupõe igualdade, liberdade, pluralidade, diversidade, respeito, justiça social, solidariedade e sustentabilidade" (Art. $3^{\circ}$ ).

Ademais, a base curricular comum da Educação Básica também foi redefinida, assim como foram estabelecidas as atribuições das diferentes etapas e modalidades da Educação Básica. Também foram reforçadas a necessidade de promoção da intersetorialidade, da ampliação da participação, da construção da gestão democrática no ensino e da valorização dos profissionais da educação; estabelecidos os diferentes 
mecanismos de avaliação - da aprendizagem, institucional interna e externa, e das redes -; e consagrado como princípio a inseparabilidade entre o cuidar e o educar.

A formação de professores ganhou novo impulso com as criações da Universidade Aberta do Brasil (UAB) (de capacitação aos demais profissionais da educação básica) e do Plano Nacional de Formação de Professores da Educação Básica (PARFOR), responsáveis por ofertar cursos de formação inicial e continuada a docentes e na modalidade de EAD (educação à distância), conduzidos em regime de parceria pelas universidades públicas com os municípios. Entretanto, apesar da iniciativa pública, multiplicaram-se os cursos privados, de curta duração e baixo custo, em razão das dificuldades encontradas pelos alunos em serem aprovados nos processos seletivos das universidades públicas; da oferta de cursos noturnos; e do apoio governamental concedido através dos programas de financiamento e pagamento de matrículas nas instituições privadas (BARRETO, 2011).

No âmbito do Ensino Superior, o presidente e sua equipe não conseguiram reverter o modelo neoliberal disseminado pelos organismos multilaterais. Estabeleceram, assim, uma política "híbrida", articulando ações em favor tanto da expansão do setor público quanto do setor privado. Isto posto, o MEC instituiu o Sistema Nacional de Avaliação do Ensino Superior (SINAES); promulgou as Leis de Inovação Tecnológica (n. 10.973 de 2004) e de regulação das Parcerias Público-Privadas (11.079 de 2004); criou o Programa Universidade para Todos (PROUNI), articulado à ampliação do Fundo de Financiamento ao Estudante do Ensino Superior (FIES); integrou os centros federais de educação tecnológica à Educação Superior; fundou novas universidades e implementou o controverso Programa de Apoio a Planos de Reestruturação e Expansão das Universidades Federais (REUNI) ${ }^{9}$, alvo de inúmeras críticas da comunidade acadêmica, cujas consequências seriam a precarização das universidades federais (LIMA, 2011)

Esses esforços governamentais levaram o país a alcançar o ciclo virtuoso prometido no início da primeira gestão, que, por pouco, não foi interrompido pela grave crise econômica que acometeu os Estados Unidos em 2008 e, posteriormente, os demais países.

A experiência petista à frente da Presidência da República foi marcada não só pela estabilidade econômica, pela boa imagem do país no plano externo e pelo combate à pobreza, que e possibilitou a amplos setores da sociedade, historicamente marginalizados, o atendimento a suas demandas pelo aparelho estatal. Nesse sentido, é possível concordar com a análise de Singer (2012). Lula e sua equipe não compactuaram com o "reformismo forte", que havia possibilitado, por exemplo, o reconhecimento dos direitos sociais na Constituição de 1988.

Não houve ruptura sistêmica, mas houve significativa redução da pobreza e um esforço de conciliação que permitiu "expansão do mercado interno com integração do subproletariado ao proletariado via emprego (mesmo que precário), consumo e crédito, sem reformas anticapitalistas, e com lenta queda da desigualdade como subproduto" (SINGER, 2012, p. 200). Por conseguinte, os mais ricos não foram ameaçados, e os mais pobres, diferentemente do que ocorrera até então, foram atendidos em demandas ligadas à efetivação de direitos sociais, além de serem rapidamente integrados à sociedade de consumo. As contradições não foram superadas - são inerentes ao capitalismo -, no entanto o país deu mostras de reduzir sua acintosa dívida social e construir um futuro diferente.

\section{O primeiro governo Lula (2003-2007) e os primeiros avanços na Educação} Especial rumo à concepção inclusiva 
Logo no primeiro ano de mandato do presidente Lula, o MEC lançou o programa Educação Inclusiva: Direito à Diversidade. Este deveria ser responsável pela formação de gestores e educadores para a oferta do atendimento educacional especializado e a garantia da acessibilidade. Seu diferencial seria a concepção pedagógica inclusiva que deveria nortear os cursos, pautada no direito de todos à educação. Desse modo, mediante seminários nacionais e cursos regionais, que desenvolviam um amplo conjunto de temáticas ${ }^{10}, 94.695$ profissionais da educação de 5.564 municípios seriam atendidos pelo programa entre 2003 e 2007 (MEC), apesar de seus diversos problemas de implementação - divergências entre as concepções de inclusão, insuficiência de recursos financeiros, entre outros (CAIADO e LAPLANE, 2009).

$\mathrm{Na}$ sequência, foi lançado o Programa de Complementação ao Atendimento Educacional Especializado às Pessoas Portadoras de Deficiência (PAED), instituído pela Lei n. 10.845 de 05 de março de 2004, com o objetivo de garantir a universalização do Atendimento Educacional Especializado (AEE). Contudo, àquela altura ainda se previa a oferta do AEE como um serviço educacional segregado, podendo somente ser incluído o aluno que fosse considerado "capaz" de se integrar à sala de aula comum. Além disso, preservava-se a histórica lógica - legitimada pela Lei de Diretrizes e Bases (LDB) e pelo FUNDEF - da transferência de recursos estatais para iniciativa privada, através do repasse de recursos às entidades privadas, para "construções, reformas, ampliações e aquisição de equipamentos" (Art. $3^{\circ}$, Inciso II) e a cessão de professores e profissionais da rede pública, de material didático e transporte escolar.

Também foram realizados investimentos em formação e certificação de professores e na elaboração de materiais voltados à gestão da educação. Os docentes que atuam com alunos com deficiência visual e auditiva foram contemplados com programas de formação continuada; foi criado o Exame Nacional de Proficiência em LIBRAS, voltado aos docentes da educação superior, visto que a língua havia sido reconhecida como idioma oficial no país - através da regulamentação da Lei n. 10.436 de 24 de abril de 2002 pelo Decreto n. 5.626 de 22 de dezembro de 2005 - e incluída nos cursos de fonoaudiologia e formação de professores; e lançada a série Educação Inclusiva, composta de quatro cadernos que abordavam o planejamento da gestão da educação em diferentes aspectos e afirmavam uma concepção de Educação Especial fundamentada na lógica dos direitos humanos.

Embora a Educação Especial tenha ganhado um espaço diferenciado na agenda governamental, foram escassos os recursos destinados à área durante o primeiro mandato de Lula ${ }^{11}$, devido, sobretudo, à restrição orçamentária imposta pela política econômica. Isso não impediu que, além dos programas supracitados, o MEC implantasse 626 Salas de Recursos Multifuncionais para o AEE; distribuísse kits pedagógicos aos alunos com deficiência visual e livros adaptados ao Braille e à LIBRAS; estruturasse 27 Núcleos de Atividades de Altas Habilidades/Superdotação (NAAH/S) e 30 Centros de Formação de Professores e Atendimento aos Alunos com Surdez (CAS); e instalasse 1,1 mil laboratórios de informática em escolas públicas através do Programa Nacional de Informática na Educação Especial (SILVA, 2007).

Em 2005, com a criação do Programa de Acessibilidade na Educação Superior, a educação superior começa a deixar de ser inatingível para a pessoa com deficiência. $\mathrm{O}$ objetivo do programa seria o de incentivar a criação e a consolidação de núcleos de acessibilidade nas instituições federais de ensino superior, de modo a contribuir para a eliminação dos diferentes tipos de barreira que impedem o acesso e a permanência dos estudantes com deficiência, e a implantação de uma política de Educação Especial, na perspectiva da Educação Inclusiva, na educação superior. Em razão disso, o MEC se 
comprometeria com a abertura de editais anuais para as universidades apresentarem suas propostas e, caso aprovadas, recursos seriam disponibilizados para a abertura dos núcleos (GARCIA e MICHELS, 2011). No entanto, pesquisa recente junto a alunos com deficiência de 13 universidades federais e estaduais, elaborada por Castro e Almeida (2014, p. 190) aponta que ainda há uma grande lacuna entre "a realidade vivenciada no contexto acadêmico e as determinações estabelecidas pelos dispositivos legais".

A articulação entre educação e trabalho também esteve na pauta governamental. A pessoa com deficiência foi incluída como público-alvo do programa Escola de Fábrica e o Programa Educação, Tecnologia e Profissionalização para Pessoas com Necessidades Educacionais Especiais foi mantido. Também foram criados cinco centros de referência, um banco de recursos humanos para encaminhamento profissional, e as escolas técnicas federais e os centros federais de educação tecnológica foram estimulados a incluir alunos com deficiência. Com isso, vislumbrava-se criar oportunidades de inserção produtiva, o que acabou ocorrendo de forma tímida, devido, entre outras coisas, ao baixo número de matrículas nessas instituições de ensino e à ausência de recursos financeiros, formação e capacitação dos recursos humanos envolvidos no programa.

Afora as realizações específicas ao campo educacional, o governo Lula também empreendeu ações importantes para a construção de uma sociedade inclusiva. Foram preservados os programas de proteção socioassistencial voltados às pessoas com deficiência - dentre os quais se destaca a política de concessão de Benefícios de Prestação Continuada -; implantaram-se novas modalidades de atendimento - "Centro-dia, CasaLar, reabilitação na comunidade, atendimento domiciliar, residência com família acolhedora e abrigos para pequenos grupos" (SILVA, 2004, p. 150) - articuladas ao Sistema Único de Assistência Social e à Política Nacional de Habilitação e Reabilitação; o Programa Nacional de Acessibilidade foi reeditado; e diversos projetos foram desenvolvidos nas áreas de telecomunicações, esportes, cultura e habitação.

A ampliação da participação social na defesa dos direitos da pessoa com deficiência também fez parte da agenda governamental. Foram implantados conselhos estaduais e municipais de Direitos da Pessoa com Deficiência, além da realização de conferências, encontros e da comemoração, em 2004, do Ano Ibero-Americano das Pessoas com Deficiência. Ainda nesse período, se deram os encaminhamentos iniciais do projeto do Estatuto da Pessoa com Deficiência, de tramitação conturbada no Congresso Nacional que só veio à sanção presidencial em 2015 -, e a realização da I Conferência Nacional dos Direitos da Pessoa com Deficiência.

Essas mobilizações se articularam às mobilizações internacionais, que tiveram na Convenção das Nações Unidas sobre os Direitos das Pessoas com Deficiência ${ }^{12}$, realizada em 2006, um importante respaldo pró-inclusão. Dentre as contribuições da Convenção estava uma nova conceituação da deficiência, agora entendida como um "conceito em evolução", resultante da "interação entre pessoas com deficiência e as barreiras devidas às atitudes e ao ambiente que impedem a plena e efetiva participação dessas pessoas na sociedade em igualdade de oportunidades com as demais pessoas" (preâmbulo, item $\mathrm{f}$ ), a reafirmação de inúmeros direitos, dentre os quais está o direito à educação, numa clara sinalização de que os Estados-partes deveriam assumir o desafio de construir a educação inclusiva, e da importância da adoção do "desenho universal", que, segundo o Artigo 2, significa a "concepção de produtos, ambientes, programas e serviços a serem usados, até onde for possível, por todas as pessoas sem necessidade de adaptação ou projeto específico" (ORGANIZAÇÃO DAS NAÇÕES UNIDAS, 2006) ${ }^{13}$. Assim sendo, não mais haveria espaço para a oferta de serviços educacionais segregados como a Educação Especial historicamente se constituíra, cabendo aos países o desafio de reformular seus 
sistemas educacionais dentro de uma concepção inclusiva, o que implicou em compreender a pessoa com deficiência como portadora de direitos, cuja participação em todas as instâncias da vida em sociedade deveria ser efetivada, tal qual já sinalizara o governo brasileiro durante o primeiro quatriênio de mandato do presidente Lula.

\section{A Política de Educação Especial no segundo governo Lula (2007-2011): o grande salto para a inclusão da pessoa com deficiência}

Após a reeleição de Lula, garantida a permanência do ministro Fernando Haddad, da maior parte de sua equipe, a Educação Especial ganhou reforço financeiro com a inclusão no FUNDEB, no $P D E$ e sua manutenção no Programa Dinheiro Direto na Escola. A inclusão no novo fundo previa três grandes ações: a implantação das Salas de Recursos Multifuncionais, destinadas à oferta do AEE nas escolas comuns; o programa Olhar Brasil, que previa a articulação entre os Ministérios da Educação e da Saúde para "identificar os alunos com problemas de visão e distribuir óculos gratuitamente" (SAVIANI, 2007, p. 1236); e, finalmente, o Programa de Acompanhamento $e$ Monitoramento do Acesso e Permanência na Escola de Pessoas com Deficiências Beneficiárias do Benefício de Prestação Continuada da Assistência Social.

Este último programa alterou o mecanismo de funcionamento do Benefício de Prestação Continuada, de modo a estabelecer a articulação entre os diferentes entes federativos com vistas a identificar crianças e adolescentes com deficiência que estivessem fora da escola ${ }^{14}$ e recebessem o benefício. A partir de então, esses indivíduos seriam incluídos, num esforço intersetorial, que deveria articular "políticas de educação, saúde, assistência social e direitos humanos" (SILVA, 2009, p. 137), naquele que programa que ficaria conhecido como BPC na Escola. Na sequência, o governo criou o BPC Trabalho, com vistas a alavancar o acesso da pessoa com deficiência ao mercado de trabalho e manter o combate à desigualdade social, visto que se permitia, a partir de então, a possibilidade de acumulação do benefício com outros tipos de pensões de caráter indenizatório (SILVA, 2009).

Um novo marco institucional foi lançado em 2008: a Política Nacional de Educação Especial na Perspectiva da Educação Inclusiva. O documento acabou por reforçar as diretrizes da Convenção das Nações Unidas sobre as Pessoas com Deficiência $^{15}$, do PDE e do Compromisso Todos pela Educação ${ }^{16}$ ao reafirmar o "o direito de todos os alunos de estarem juntos, aprendendo e participando, sem nenhum tipo de discriminação" (BRASIL, 2008, p. 05) e redefinir o público-alvo da Política ${ }^{17}$ num claro entendimento de que as "pessoas se modificam continuamente transformando o contexto no qual se inserem", não se limitando, portanto à "mera categorização e especificações atribuídas a um quadro de deficiência, transtornos, distúrbios e aptidões" (BRASIL, 2008, p. 15), característico da evolução da Educação Especial e do predomínio da concepção médico-assistencialista em sua oferta no decorrer do tempo.

O paradigma educacional da inclusão viria a substituir o da integração - que previa a inclusão parcial, conforme a capacidade de adaptação do aluno à escola comum -, presente desde o final da década de 1970 no país. Em razão disso, a Educação Especial teria agora uma nova definição, agora compreendida como

modalidade de ensino que perpassa todos os níveis, etapas e modalidades, realiza o atendimento educacional especializado, disponibiliza os serviços e recursos próprios desse atendimento e orienta os alunos e seus 
professores quanto a sua utilização nas turmas comuns do ensino regular. (BRASIL, 2008, p. 16)

Conforme essa concepção, não faria mais sentido a existência de instituições especializadas, escolas e classes especiais substituindo a escola comum. Tampouco deveriam subsistir práticas pedagógicas segregacionistas, homogeneizantes, discriminatórias, preconceituosas e excludentes. $\mathrm{O}$ aluno deveria construir sua autonomia, praticar seus direitos e ser respeitado em sua diferença. Em função desses pressupostos, a política estabeleceu como objetivos:

assegurar a inclusão escolar de alunos com deficiência, transtornos globais do desenvolvimento e altas habilidades/superdotação, orientando os sistemas de ensino para garantir: acesso ao ensino regular, com participação, aprendizagem e continuidade nos níveis mais elevados do ensino; transversalidade da modalidade de Educação Especial desde a educação infantil até a educação superior; oferta do atendimento educacional especializado; formação de professores para o atendimento educacional especializado e demais profissionais da educação para a inclusão; participação da família e da comunidade; acessibilidade arquitetônica, nos transportes, nos mobiliários, nas comunicações e informação; e articulação intersetorial na implementação das políticas públicas (BRASIL, 2008, p. 14).

Num esforço inédito, a Política previa a articulação com a educação indígena, rural e quilombola e a garantia da oferta desde a Educação Infantil até o Ensino Superior, etapa em que o acesso e a permanência do alunado devem ser efetivadas por meio de ações que promovam a quebra das barreiras arquitetônicas, sociais, comunicacionais e atitudinais desde os processos seletivos ao "desenvolvimento de todas as atividades que envolvem o ensino, a pesquisa e a extensão" (BRASIL, 2008, p. 17).

Os indivíduos com deficiência auditiva foram atendidos em demandas específicas pela nova política. Garantiu-se a incorporação da LIBRAS ao ensino escolar, devendo a Língua Portuguesa ser ensinada como segunda língua na modalidade escrita para os alunos surdos; o direito ao convívio com outros surdos nas turmas comuns, sempre que possível; e a disponibilização, pelas escolas, dos "serviços de tradutor-intérprete de Libras e Língua Portuguesa" e do "ensino da Libras para os demais alunos" (BRASIL, 2008, p. 17). Os alunos com deficiência visual também foram contemplados com a garantia de realização do AEE por profissionais com conhecimentos específicos do "sistema Braille, do soroban [ábaco japonês], da orientação e mobilidade, das atividades de vida autônoma, [...] da tecnologia assistiva e outros" (BRASIL, 2008, p. 17). Além disso, os sistemas de ensino deveriam "disponibilizar as funções de instrutor, tradutor/intérprete de Libras e guia intérprete, bem como de monitor ou cuidador aos alunos com necessidade de apoio nas atividades de higiene, alimentação, locomoção" (idem), com vistas a assegurar o pleno atendimento das necessidades do alunado.

O AEE, no contexto da nova política, não seria substituto da escola comum, como historicamente ocorrera, fato que oportunizou às instituições especializadas $\mathrm{o}$ protagonismo na educação da pessoa com deficiência. Caberia ao serviço identificar, elaborar e organizar recursos pedagógicos e de acessibilidade mediante a realização de atividades diferentes das que ocorrem na sala de aula, tendo por objetivo complementar e/ou suplementar a formação do alunado em articulação com a proposta pedagógica do ensino comum (BRASIL, 2008). Nessa direção, o AEE deveria ocorrer no interior da 
escola comum, na Sala de Recursos Multifuncionais (SRM), dotada de recursos, equipamentos, mobiliários, materiais didático-pedagógicos e de acessibilidade, necessários para o pleno atendimento ao alunado.

A formação docente também recebeu especial atenção da nova Política. Parte da comunidade educacional ansiava por uma transformação radical no modelo dicotômico de formação presente até então. A atuação na Educação Especial, na perspectiva da Educação Inclusiva, exige "formação, inicial e continuada, conhecimentos gerais para o exercício da docência e conhecimentos específicos da área" (BRASIL, 2008, p. 17). Ou seja, o profissional não mais deveria ser formado para trabalhar pautado, exclusivamente, na deficiência, mas em todo o fenômeno educacional, de modo a ter condições de trabalhar de articuladamente com o ensino regular.

Os desdobramentos desse novo marco institucional foram inevitáveis. A partir de então, o MEC centrou esforços em quatro eixos: a reestruturação do Atendimento Educacional Especializado - mediante a instituição do Decreto n. 6.571 de 17 de setembro de 2008 e das Diretrizes Operacionais da Educação Especial para o Atendimento Educacional Especializado —; a implantação das Diretrizes Curriculares Nacionais para a Educação Básica; a criação de Salas de Recursos Multifuncionais; e o investimento em formação de professores.

O Decreto n. 6.571 de 17 de setembro de 2008 determinou que a União deverá prestar assistência técnico-financeira ${ }^{18}$ aos sistemas públicos de educação comum com o objetivo de assegurar a oferta do AEE - sem dúvida, um avanço institucional. Para tanto, o atendimento foi redefinido como "conjunto de atividades, recursos de acessibilidade e pedagógicos organizados institucionalmente, prestado de forma complementar ou suplementar à formação dos alunos no ensino regular" (Art. $1^{\circ}$, parágrafo $1^{\circ}$ ). Afora isso, o AEE deveria envolver a participação da família e ser realizado intersetorialmente - outra importante inovação institucional.

Outro aspecto importante diz respeito à alteração do Decreto n. 6.253 de 13 de novembro de 2007, que instituiu o FUNDEB, pois, a partir de 2010, admitir-se-ia a modificação do cálculo do financiamento, agora dado em função do "cômputo das matrículas dos alunos da educação regular da rede pública que recebem atendimento educacional especializado, sem prejuízo do cômputo dessas matrículas na educação básica regular" (BRASIL, 2008). Desse modo, só receberiam recursos do Fundo os entes federados que assegurassem a matrícula dos alunos no ensino comum e no AEE. Entretanto, mesmo avançando na concepção inclusiva, a legislação manteve a disposição em financiar as instituições especializadas privadas conveniadas com os estados e municípios, o que prejudica até hoje a implantação do atendimento pelo Poder Público ${ }^{19}$.

No ano seguinte, a Resolução n. 4 de 12 de outubro de 2009 acabou por instituir as Diretrizes Operacionais para o AEE na Educação Básica. O documento, dentre outras medidas, redefiniu o conceito de acessibilidade aplicado à educação ${ }^{20}$; determinou que tanto a elaboração quanto a execução do plano de AEE seria de competência do professor que atua na Sala de Recursos Multifuncionais, mas deveria envolver o trabalho conjunto com outros docentes, a participação da família e ser articulada intersetorialmente com os serviços de saúde, assistência social, etc. (Art. $9^{\circ}$ ); a necessidade de uma formação mínima que habilite o profissional para o exercício da docência e formação específica para a Educação Especial (Art. 12\%), medida de fundamental importância para o fortalecimento do processo pedagógico e a ruptura com o caráter assistencialista da modalidade; e estabeleceu novas atribuições ao professor do AEE (Art. $13^{\circ}$ ). Por fim, seria preciso organizar o serviço com base nas diretrizes do Art. $10^{\circ}$ : 
I - sala de recursos multifuncionais: espaço físico, mobiliário, materiais didáticos, recursos pedagógicos e de acessibilidade e equipamentos específicos;

II - matrícula no AEE de alunos matriculados no ensino regular da própria escola ou de outra escola;

III - cronograma de atendimento aos alunos;

IV - plano do AEE: identificação das necessidades educacionais específicas dos alunos, definição dos recursos necessários e das atividades a serem desenvolvidas;

$\mathrm{V}$ - professores para o exercício da docência do AEE;

VI - outros profissionais da educação: tradutor e intérprete de Língua Brasileira de Sinais, guia-intérprete e outros que atuem no apoio, principalmente às atividades de alimentação, higiene e locomoção;

VII - redes de apoio no âmbito da atuação profissional, da formação, do desenvolvimento da pesquisa, do acesso a recursos, serviços e equipamentos, entre outros que maximizem o AEE.

As Diretrizes Curriculares Nacionais para a Educação Básica consubstanciariam, por sua vez, as teses favoráveis à inclusão. Em uma seção reservada exclusivamente à Educação Especial, o artigo 29 reafirmou o modelo de organização da modalidade, sua transversalidade a todos os níveis, etapas e modalidades de ensino; a integração à educação regular; a inclusão total como um princípio; e o estabelecimento do AEE, de forma complementar ou suplementar à escolarização, nas Salas de Recursos Multifuncionais ou "em centros de AEE da rede pública ou de instituições comunitárias, confessionais ou filantrópicas sem fins lucrativos" (BRASIL, 2010), a acessibilidade como um principio e a intersetorialidade das políticas públicas. Ademais, o parágrafo segundo determinou que os sistemas e as instituições de ensino deveriam "criar condições para que o professor da classe comum possa explorar as potencialidades de todos os estudantes, adotando uma pedagogia dialógica, interativa, interdisciplinar e inclusiva" (idem), além de definir as atribuições do professor de Atendimento Educacional Especializado: "identificar habilidades e necessidades dos estudantes, organizar e orientar sobre os serviços e recursos pedagógicos e de acessibilidade para a participação e aprendizagem dos estudantes" (ibidem).

Milhares de Salas de Recursos Multifuncionais foram criadas como consequência da Política Nacional de Educação Especial na Perspectiva da Educação Inclusiva. Somente em 2008, foram contempladas 4.300 escolas, sendo 792 estaduais e 3.508 municipais. No ano seguinte, mais 15 mil escolas receberam salas e, em 2010, outras 3.750 (MEC) - através de um programa voltado especificamente para tal objetivo, vinculado ao $P D E$, que acabou incentivando a oferta pública do serviço e diminuindo a participação das instituições privadas na Educação Especial.

Foram ampliados os programas de formação, visando ampliar a qualificação dos professores, sobretudo para o AEE. Como consequência, o Programa Educação Inclusiva: Direito à Diversidade recebeu maiores investimentos, embora fosse um instrumento questionável de formação, foi criado o Programa Nacional de Formação Continuada de Professores da Educação Especial, cujo objetivo era o de "formar professores dos sistemas estaduais e municipais de ensino para o atendimento educacional especializado" (BRASIL, 2007) por meio de cursos de extensão, aperfeiçoamento e especialização, com duração mínima de 120 horas, ofertados pelas instituições de Ensino Superior que tivessem seus projetos aprovados pelo MEC. Além disso, surgiu como principal iniciativa um programa destinado à formação de professores para o AEE, também disponibilizado na modalidade 
EAD. Entretanto, o que deveria diferenciá-lo dos demais diz respeito à metodologia dos cursos ofertados. Em vez de um modelo de aprendizagem pautado exclusivamente nos conteúdos, a proposta é que se realizassem cursos pautados em metodologias ativas de aprendizagem, de modo a trazerem "novas formas de produção e organização do conhecimento" (MANTOAN et al., 2010, p. 29).

Embora esse modelo não garantisse a necessária transformação radical da formação docente, visto que, no Brasil, as licenciaturas tenderam a relegar a Educação Especial ao segundo plano, disponibilizando, na maioria das vezes, disciplinas em caráter optativo (BUENO, 2002; SILVA, 2009 apud BUIATTI, 2013), um grande público foi alcançado pelos programas implementados pela gestão Lula - em 2008, 30 mil professores da rede pública; no ano seguinte, outros 19.350 (BRASIL, 2009; 2010).

Outras ações relevantes foram implementadas: distribuição de livros didáticos voltados à alfabetização em LIBRAS, computadores para alunos deficientes visuais dos anos finais do Ensino Fundamental e do primeiro ano do Ensino Médio e o projeto Livro Acessível foi criado com o objetivo de distribuir livros em Braille e no formato digital. Também foi implantado o programa Escola Acessivel, que, com recursos do PDDE somente em somente em 2009 foram investidos mais de 37 milhões de reais (SILVA, 2010) - readequou, com base nos novos padrões de acessibilidade, milhares de escolas em todo o país.

Ainda no que concerne à acessibilidade, o governo Lula apresentou novas realizações durante o segundo quatriênio: a criação da campanha Acessibilidade: siga essa ideia, a ampliação do Programa Nacional de Acessibilidade e a implantação do Projeto Básico de Escola/Ponto de Parada, responsável pela concessão de subsídios aos municípios para a adequação dos mobiliários urbanos dos terminais rodoviários ou metroviários às escolas públicas (SILVA, 2010).

A empregabilidade das pessoas com deficiência se manteve como preocupação recorrente durante o segundo mandato. O governo ampliou a fiscalização ao cumprimento da Lei de Cotas, provocando a inserção de milhares de indivíduos no mercado de trabalho $^{21}$, determinou a inclusão dos alunos com deficiência no Projovem e elaborou um projeto de incentivo à aprendizagem, cujos resultados, todavia, só seriam observados na gestão seguinte.

Por fim, e não menos importante, a preocupação com a ampliação da participação social na defesa dos direitos da pessoa com deficiência foi preservada. A CORDE foi transformada, inicialmente, em Subsecretaria Nacional de Promoção dos Direitos da Pessoa com Deficiência, e, posteriormente, em Secretaria Nacional de Promoção dos Direitos da Pessoa com Deficiência, órgão vinculado à Secretaria de Estado dos Direitos Humanos - um importante avanço na estrutura institucional. Por sua vez, o CONADE realizou, em 2008, a II Conferência Nacional dos Direitos da Pessoa com Deficiência, cujo tema foi "Inclusão, Participação e Desenvolvimento: Um Novo Jeito de Avançar" e cujas deliberações foram incorporadas posteriormente ao Plano Nacional dos Direitos da Pessoa com Deficiência - Viver sem Limites, criado e implementado durante a administração de Dilma Rousseff.

\section{Considerações Finais}

A construção de um sistema educacional inclusivo é um desafio que vai muito além da inserção do alunado com deficiência na escola comum e essa compreensão Lula e sua equipe tiveram durante os oito anos à frente da Presidência da República. Daí a implantação, não sem contradições, de um modelo de atuação na educação comum, 
expresso na inédita formulação de programas e ações para indígenas, camponeses, quilombolas, jovens e adultos, entre outros, que reafirmou o direito de todos à educação diretriz expressa pela Constituição Federal de 1988. Todavia, sendo a educação um fenômeno concreto, influenciado por diferentes fatores - econômicos, políticos, sociais e culturais, como citei anteriormente - e o Brasil, um país historicamente marcado pela desigualdade social e pelos graves problemas educacionais, não se constrói um sistema educacional inclusivo "da noite para o dia".

O saldo da era Lula foi positivo para a democratização das oportunidades educacionais e, mais especificamente, para a inclusão da pessoa com deficiência na educação comum. O presidente e sua equipe avançaram na construção de uma agenda inclusiva ao estabelecer um conjunto de políticas e programas para a Educação Infantil, o Ensino Fundamental, o Ensino Médio, a Educação de Jovens e Adultos e o Ensino Superior, que ampliaram o acesso do público aos serviços públicos, mas não ainda não equalizaram o problema da qualidade do ensino - questão que deverá ser enfrentada pelas próximas gestões.

No tocante à educação da pessoa com deficiência, esta não mais foi concebida de forma restrita à Educação Especial, segregada, ofertada nas instituições especializadas ou nas classes especiais, tanto no âmbito público quanto no privado. Por conseguinte, a Política Nacional de Educação Especial na Perspectiva da Educação Inclusiva foi formulada, cujos desmembramentos - a redefinição do AEE, a implantação de Salas de Recursos Multifuncionais e de programas de formação de professores - tiveram impactos favoráveis: em 2010 havia 702.603 alunos com algum tipo de deficiência matriculados em instituições educacionais, dos quais 484.332 (68,93\%) se encontravam incluídos na educação comum (MEC).

Embora esses números reflitam uma mudança expressiva, ainda não se pode afirmar, definitivamente, que temos um sistema educacional inclusivo, que garante educação de qualidade a todos os indivíduos. Os desafios são evidentes, sobretudo no que diz respeito ao sistema público; recursos destinados à área educacional ainda que vultosos, ainda não correspondem ao montante satisfatório às demandas históricas; docentes possuem formações de qualidade questionável, baixíssimas remunerações e péssimas condições de trabalho; currículos e mecanismos de avaliação refletem o compromisso da educação escolar com a reprodução das teses capitalistas, frustrando projetos pedagógicos de caráter emancipatório. Desse modo, as instituições de ensino permanecem distantes desinteressantes e, muitas vezes, desinteressadas - da realidade do alunado, sem se abrir à participação e à transformação social.

Portanto, cabe ressaltar que a escola inclusiva não é aquela que deve atender adequadamente a pessoa com deficiência e, sim, a instituição educacional que assegura a todos e todas uma formação de qualidade num ambiente público, laico e gratuito. Nos anos Lula, o Estado encaminhou um projeto que questionou algumas barreiras historicamente impostas e concedeu à educação maior espaço na agenda governamental, embora este ainda não seja o desejável em face do amplo conjunto de demandas reprimidas durante décadas pelo aparelho estatal e da crescente participação do setor privado nos diferentes níveis de ensino - vide a expansão desordenada da educação superior nos últimos anos, para citar apenas um exemplo. Todavia, em meio a muitas lutas - a luta por uma educação de qualidade é permanente -, gradualmente se caminha para uma sociedade em que todos os indivíduos possam dela participar ativamente, exercendo seus direitos em plenitude, incluídos na educação comum. 


\section{Referências}

AMARAL, Oswaldo Martins Estanislau. As transformações na organização interna do Partido dos Trabalhadores entre 1995 e 2009. 293 f. Tese (Doutorado) - Curso de Ciências Sociais, Universidade Estadual de Campinas, 2010.

BARRETO, Elba Siqueira de Sá. Políticas e práticas de formação de professores da educação básica no Brasil: um panorama nacional. Revista Brasileira de Política e Administração da Educação, Anpae, Recife, v. 27, n. 1, 2011.

BUENO, José Geraldo Silveira. Crianças com necessidades educativas especiais, política educacional e a formação de professores: generalistas ou especialistas. Revista Brasileira de Educação Especial, v. 3, n. 5, p. 7-25, 1999.

BUIATTI, Viviane Prado. Atendimento educacional especializado: dimensão política, formação docente e concepções dos profissionais. $324 \mathrm{f}$. Tese (Doutorado) Universidade Federal de Uberlândia, Uberlândia, 2013.

BRASIL. Política Nacional de Educação Especial na Perspectiva da Educação Inclusiva. Brasília, DF. 2008.2 Disponível em:<http://portal.mec.gov.br/seesp/arquivos/pdf/politica.pdf $>$. Acesso em: 15 jan. 2014.

CAIADO, Katia Regina Moreno \& DE LAPLANE, Adriana Lia Friszman. Programa Educação inclusiva: direito à diversidade - uma análise a partir da visão de gestores de um município-polo. Educação e Pesquisa, v. 35, n. 2, p. 303-315, 2009.

DOURADO, Luiz Fernandes. Políticas e gestão da educação básica no Brasil: limites e perspectivas. Educação e Sociedade, Campinas, v. 28, n. 100, out. 2007.

FIGUEIREDO, Rubens \& COUTINHO, Ciro. A eleição de 2002. Opinião Pública, Campinas, v. 9, n. 2, p. 93-117, 2003.

FREIRE, Paulo. Pedagogia do oprimido. 17.ed. Rio de Janeiro: Paz e Terra, 2013.

GARCIA, Rosalva Maria C. \& MICHELS, Maria Helena. A política de Educação Especial no Brasil (1991-2011): análise da produção do GT15 - Educação Especial da ANPEd. Revista Brasileira de Educação Especial, Marília, v. 17, p. 105-124, jan.-mar. 2011.

LEHER, Roberto. Educação no governo de Lula da Silva: a ruptura que não aconteceu. Os anos Lula: contribuições para um balanço crítico 2003-2010. 1. ed. Rio de Janeiro: Garamond, 2010, p. 369-412.

LIMA, Kátia Regina de Souza. O Banco Mundial e a educação superior brasileira na primeira década do novo século. Revista Katálysis, Florianópolis, v. 14, n. 1, p. 86-94, 2011.

MANTOAN, Maria Teresa Eglér et al. A educação especial na perspectiva da inclusão escolar: a escola comum inclusiva. Brasília: Ministério da Educação, v. 1, 2010.

MEC. www.mec.gov.br

MOEHLECKE, Sabrina. As políticas de diversidade na educação no governo Lula. Cadernos de Pesquisa, São Paulo, v. 39, n. 137, p.461-487, 2009.

NOVELLI, José Marcos Nayme. A questão da continuidade da política macroeconômica entre o governo Cardoso e Lula (1995-2006). Revista de Sociologia e Política, v. 18, n. 36, p. 227-240, 2010. 
NOSELLA, Paolo. Ensino médio: em busca do princípio pedagógico. Educação \& Sociedade, Campinas, v. 32, n. 117, p. 1051-1066, 2011.

ORGANIZAÇÃO DAS NAÇÕES UNIDAS. Convenção Internacional sobre os Direitos
das Pessoas com $\quad$ Deficiência. <http://www.planalto.gov.br/ccivil_03/_ato2007-2010/2009/decreto/d6949.htm>.

Acessado em 23/8/2014.

PINTO, José Marcelino de Rezende. O financiamento da educação no governo Lula. Revista Brasileira de Política e Administração da Educação, Anpae, v. 25, n. 2, 2009.

POCHMANN, Marcio. Políticas sociais e padrão de mudanças no Brasil durante o governo Lula. Revista SER Social, v. 13, n. 28, p. 12-40, 2011.

SAVIANI, Dermeval. História das ideias pedagógicas no Brasil. 3. ed. revista. Campinas: Autores Associados, 2010.

O Plano de Desenvolvimento da Educação: análise do projeto do MEC. Revista

Educação \& Sociedade, Campinas, v. 28, n. 100, out. 2007. Disponível em <http://www.scielo.br/scielo.php?script=sci_arttext\&pid=S0101-

$73302007000300027 \& \operatorname{lng}=\mathrm{en} \& n r m=\mathrm{iso}>$. Acessado em 18/9/2014.

SILVA, Luiz Inácio Lula da. Carta ao povo brasileiro. 2002.

. Mensagem ao Congresso Nacional. Presidência da República do Brasil. 2004.

Mensagem ao Congresso Nacional. Presidência da República do Brasil. 2005.

Mensagem ao Congresso Nacional. Presidência da República do Brasil. 2006.

Mensagem ao Congresso Nacional. Presidência da República do Brasil. 2007.

Mensagem ao Congresso Nacional. Presidência da República do Brasil. 2008.

Mensagem ao Congresso Nacional. Presidência da República do Brasil. 2009.

Mensagem ao Congresso Nacional. Presidência da República do Brasil. 2010.

SILVA, Lázara Cristina da. Políticas públicas e formação de professores: vozes e vieses da educação inclusiva. 2009. 344 f. Tese (Doutorado) - Universidade Federal de Uberlândia, Uberlândia, 2009.

SINGER, André Vitor. Os sentidos do lulismo: reforma gradual e pacto conservador. São Paulo: Companhia das Letras, 2012.

\section{Notas}

\footnotetext{
${ }^{1}$ Doutorando em Sociologia pelo Instituto de Filosofia e Ciências Humanas (IFCH) da Universidade Estadual de Campinas, mestre em Educação pela Faculdade de Educação da mesma universidade. Contato: padilha.caio@hotmail.com

${ }^{2}$ Este trabalho é um dos frutos da pesquisa desenvolvida durante o mestrado, cujos resultados foram expressos na dissertação intitulada "Educação e Inclusão no Brasil (1985-2010)", disponível em: www.acervus.unicamp.br

${ }^{3}$ Segundo Pinto (2009, p. 329), o FUNDEB, apesar de ampliar significativamente o montante repassado pela União, não traria recursos novos: "Em termos de recursos novos da União para a educação básica, e
} 
lembrando que até $30 \%$ da sua complementação ao FUNDEB pode sair dos $18 \%$ da vinculação constitucional, esse adicional representará, a partir de 2009, cerca de $0,12 \%$ do PIB, o que é muito pouco".

${ }^{4}$ Apesar de reivindicar a condição de coletivo, o PDE não foi formulado com a participação da comunidade educacional e não foi balizado por "fundamentação técnico-pedagógica suficiente", carecendo de "articulação efetiva entre os diferentes programas e ações em desenvolvimento pelo próprio MEC e as políticas propostas” (DOURADO, 2007, p. 928).

5 O Plano de Metas Compromisso Todos pela Educação, regulamentado pelo Decreto n. 6.094 de 24 de abril de 2007, contém a maior parte das diretrizes para a educação básica, expressas em 28 metas a serem cumpridas por estados, municípios e pelo Distrito Federal em seus respectivos sistemas de ensino.

${ }^{6}$ O Índice de Desenvolvimento da Educação Básica (IDEB) foi criado em 2007 com o objetivo de aferir o nível de aprendizagem do alunado da educação básica a partir da articulação dos dados referentes ao fluxo e à aprovação escolar com as médias de desempenho no SAEB e na Prova Brasil. Segundo Pinto (2009, p. 328), esse índice foi utilizado como referência para o MEC identificar os entes federativos que deveriam ser apoiados "mais diretamente ou prioritariamente".

${ }^{7}$ Esse programa foi responsável por articular ações entre as universidades e as comunidades populares, possibilitando que os universitários, aproveitando a experiência no ensino superior, interviessem em seus respectivos territórios de origem (HENRIQUES e CAVALLEIRO, 2007).

${ }^{8}$ Esse projeto dispunha sobre a reserva de vagas nas instituições federais de ensino superior para negros, índios e alunos de escolas públicas.

9 De acordo com o governo, o REUNI deveria atuar em cinco dimensões - "i) reestruturação acadêmicocurricular; ii) inovação pedagógica; iii) mobilidade intra e interinstitucional; iv) compromisso social das IFES; e v) articulação entre graduação, pós-graduação e os demais níveis educacionais" - e estruturar-se em programas associados - Programa de Apoio à Extensão Universitária (Proext), do Programa de Educação Tutorial (PET) e do Programa Nacional de Assistência Estudantil (PNAES) (BRASIL, 2010, p. 167).

${ }^{10}$ Caiado e Laplane (2009, p. 305) especificam os eixos temáticos trabalhados nos cursos.

11 Segundo Pinto (2009), a Educação Especial recebeu, em 2003, 51 milhões de reais; em 2004, 39 milhões; em 2005, 66 milhões; e em 2006, 55 milhões de reais, quantias insuficientes, tendo-se em consideração a complexidade dos problemas enfrentados pelo setor.

${ }^{12}$ A Convenção foi ratificada pelo governo brasileiro, em forma de Emenda Constitucional, em 2008, já no segundo mandato de Lula.

13 Deve-se ressaltar que a diretriz não excluía as "ajudas técnicas para grupos específicos de pessoas com deficiência, quando necessárias" (Artigo 2).

${ }^{14}$ Os resultados iniciais do programa foram surpreendentes. Somente em 2008, "segundo pareamento de dados entre censo escolar e cadastro do BPC", eram "262.187 crianças e adolescentes com deficiência fora da escola" (SILVA, 2009, p. 137).

${ }^{15}$ Além do direito à educação, foram reafirmados os direitos à saúde; ao trabalho e ao emprego; à liberdade; à segurança; ao acesso à justiça; à proteção social; à vida independente e à inclusão na comunidade; à mobilidade; à habilitação e reabilitação; à liberdade de expressão e ao acesso à informação; à igualdade perante a lei; à participação na vida pública e política; ao lar e à família; à cultura; e ao esporte, lazer e recreação.

${ }^{16}$ Segundo a Política Nacional de Educação Especial na Perspectiva da Educação Inclusiva, no PDE é reforçada a "visão sistêmica da educação que busca superar a oposição entre educação regular e Educação Especial” (BRASIL, 2008, p. 11). Além disso, o Compromisso Todos pela Educação reforça a necessidade de se garantir o acesso e a permanência do aluno com deficiência no sistema educacional comum.

${ }^{17}$ Estabeleceu-se que os alunos com deficiência são "aqueles que têm impedimentos de longo prazo, de natureza física, mental, intelectual ou sensorial, que em interação com diversas barreiras podem ter restringida sua participação plena e efetiva na escola e na sociedade” (BRASIL, 2008, p. 15). 
18 O MEC definiu ainda as ações que apoiaria técnica e financeiramente: "I — implantação de salas de recursos multifuncionais; II — formação continuada de professores para o atendimento educacional especializado; III - formação de gestores, educadores e demais profissionais da escola para a educação inclusiva; IV - adequação arquitetônica de prédios escolares para acessibilidade; V — elaboração, produção e distribuição de recursos educacionais para a acessibilidade; e VI — estruturação de núcleos de acessibilidade nas instituições federais de educação superior" (BRASIL, 2008).

${ }^{19}$ A ocorrência do AEE deve se dar em Salas de Recursos Multifuncionais. No entanto, não são todos os sistemas que as possuem. A rede estadual de ensino de São Paulo, por exemplo, até hoje não possui salas em grande parte de suas escolas, tampouco existe um número suficiente de professores para garantir o atendimento.

${ }^{20} \mathrm{O}$ conceito de acessibilidade voltado à educação é agora entendido como o conjunto de recursos que assegura "condições de acesso ao currículo dos alunos com deficiência ou mobilidade reduzida, promovendo a utilização dos materiais didáticos e pedagógicos, dos espaços, dos mobiliários e equipamentos, dos sistemas de comunicação e informação, dos transportes e dos demais serviços” (Art. 2º parágrafo único).

${ }^{21}$ Segundo dados governamentais, de 2005 a 2008, a fiscalização trabalhista inseriu 107.325 indivíduos com deficiência no mercado de trabalho. Em 2009, mais 26.403 foram incluídos (SILVA, 2010).

Recebido: julho-15 Aprovado: dezembro-15 